\title{
Advances in Neuroprotective Strategies: Potential Therapies for Intracerebral Hemorrhage
}

\author{
Brian Y. Hwang Geoffrey Appelboom Amit Ayer Christopher P. Kellner \\ Ivan S. Kotchetkov Paul R. Gigante Raqeeb Haque Michael Kellner \\ E. Sander Connolly
}

Department of Neurological Surgery, Columbia University College of Physicians and Surgeons, New York, N.Y., USA

\section{Key Words}

Intracerebral hemorrhage $\cdot$ Pathophysiology

Neuroprotection $\cdot$ Secondary cerebral injury, mechanism

\begin{abstract}
Intracerebral hemorrhage $(\mathrm{ICH})$ is associated with higher mortality and morbidity than any other form of stroke. However, there currently are no treatments proven to improve outcomes after $\mathrm{ICH}$, and therefore, new effective therapies are urgently needed. Growing insight into $\mathrm{ICH}$ pathophysiology has led to the development of neuroprotective strategies that aim to improve the outcome through reduction of secondary pathologic processes. Many neuroprotectants target molecules or pathways involved in hematoma degradation, inflammation or apoptosis, and have demonstrated potential clinical benefits in experimental settings. We extensively reviewed the current understanding of $\mathrm{ICH}$ pathophysiology as well as promising experimental neuroprotective agents with particular focus on their mechanisms of action. Continued advances in ICH knowledge, increased understanding of neuroprotective mechanisms, and improvement in the ability to modulate molecular and pathologic events with multitargeting agents will lead to successful clinical trials and bench-to-bedside translation of neuroprotective strategies.

Copyright $\odot 2010$ S. Karger AG, Basel
\end{abstract}

\section{Introduction}

Despite ongoing medical and surgical advances, intracerebral hemorrhage (ICH) remains the deadliest and least treatable type of stroke [1]. At present, the treatment options are limited with only supportive care and rehabilitation shown to improve the outcome after $\mathrm{ICH}[2,3]$. Furthermore, therapies developed for hematoma growth prevention, clot removal or optimization of cerebral perfusion pressure have yet to conclusively demonstrate their clinical benefits in randomized clinical trials [4]. In efforts to identify novel therapeutic targets, recent investigations have focused on the mechanisms of secondary brain injury at the hemorrhage site and in the perihematomal zone (PHZ) after ICH [4]. Mounting evidence has indicated that the secondary effects of ICH involve bloodbrain-barrier (BBB) disruption, cerebral edema, inflammation autophagy, and cellular necrosis and apoptosis [5-9]. Furthermore, they are important contributors to the clinical course and outcome after ICH [5]. This had led to a rapidly growing interest in neuroprotective strategies that aim to improve outcomes by reducing $\mathrm{ICH}$ induced secondary pathologic processes.

\section{B.Y.H., G.A. and A.A. contributed equally to this article.}

\section{KARGER}

Fax +4161306 1234 E-Mail karger@karger.ch www.karger.com
Geoffrey Appelboom, MD

Columbia University, College of Physicians and Surgeons

Neurological Institute of New York, 710 West 168 Street, Room 404

New York, NY 10032 (USA)

Tel. +1 212305 4679, Fax +1 212305 2026, E-Mail ga2294@ columbia.edu 


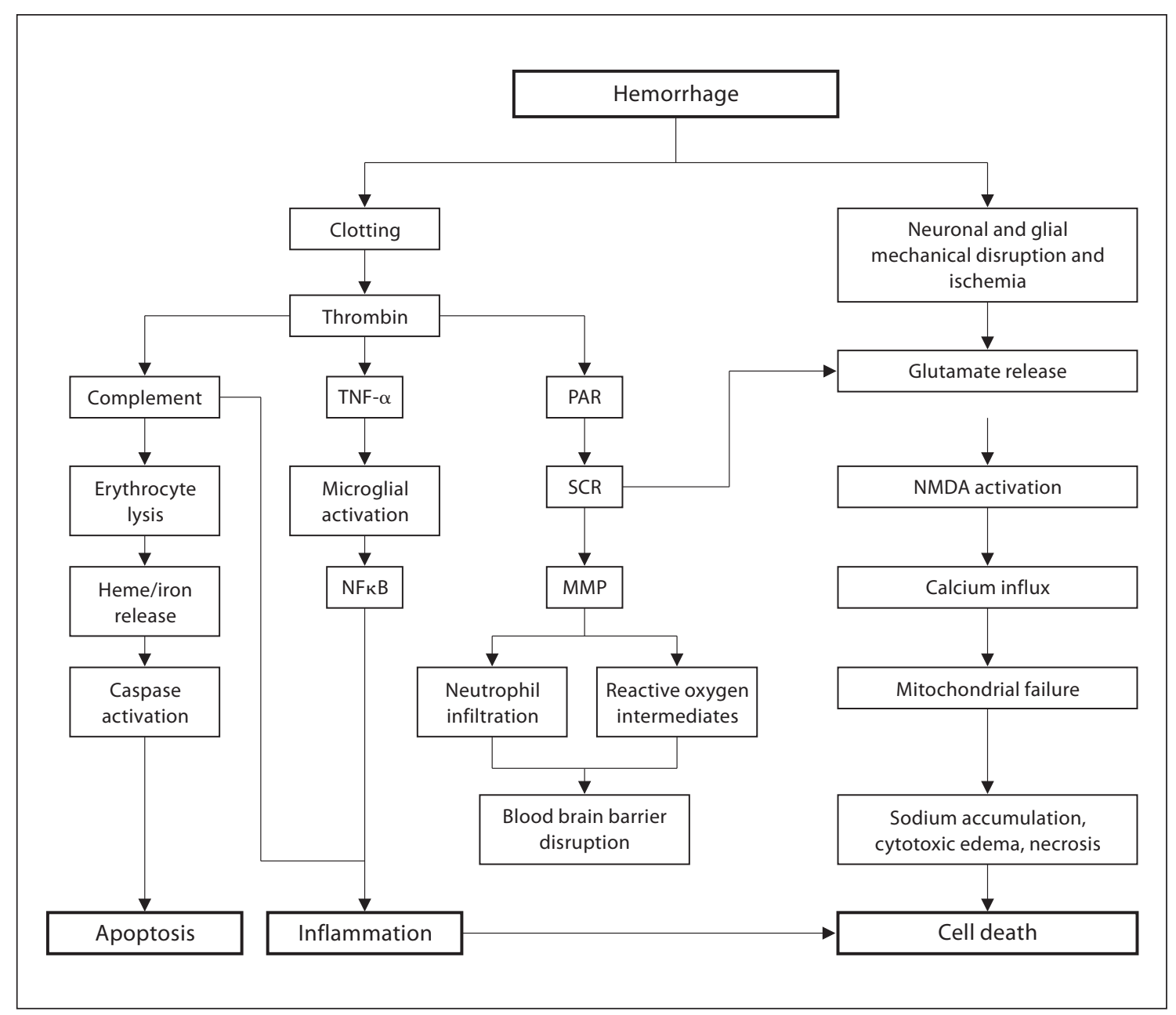

Fig. 1. Pathophysiology brain injury following $\mathrm{ICH}$. NFкB = Nuclear factor $\kappa$-light-chain-enhancer of activated $\mathrm{B}$ cells; $\mathrm{NMDA}=\mathrm{N}$-methyl-D-aspartic acid; $\mathrm{MMP}=$ matrix metalloproteinase; $\mathrm{PAR}=$ protease-activated receptor; TNF- $\alpha=$ tumor necrosis factor $-\alpha$.

Neuroprotection consists of heterogeneous strategies that modulate specific cellular and molecular pathways that are triggered after ICH $[6,10]$. Numerous neuroprotective agents have been shown to reduce cell death [11], decrease hemorrhage and edema volumes [12-14], and improve functional outcome $[15,16]$. Some are currently being investigated in clinical trials and represent novel and promising avenues of ICH therapy [4]. In this article, we review the current understanding of the pathophysiology of ICH-induced secondary brain injury. In addition, we provide an overview of putative neuroprotectants that target hematoma-derived products, inflammatory cascades or proapoptotic pathways.

\section{Mechanisms of ICH-Induced Secondary Brain Injury}

The current understanding of ICH-induced brain injury is based on both clinical and experimental studies (fig. 1). Initial injury immediately after ICH onset is from the direct mechanical force of the expanding hematoma $[4,8]$. In the first $4 \mathrm{~h}$, physical disruption and stretching of the surrounding neuronal and glial cells lead to excessive neurotransmitter release, calcium influx and mitochondrial dysfunction [8]. When severe, this results in cytotoxic edema and cellular necrosis [17]. In the ensuing days, the degrading hematoma releases its breakdown products, such as thrombin and ferrous iron, which lead to the activation of oxygen free radicals, matrix metalloproteinases (MMPs), complement proteins and inflam- 
matory markers $[4,5,8,9,18-20]$ (fig. 1). These downstream molecules increase the BBB permeability [9], recruit inflammatory cells [21], trigger apoptosis [22], and ultimately exacerbate cerebral edema and neuronal death [23].

Cerebral edema is a key component of the ICH pathophysiology (fig. 1). Its rapid development upon onset contributes significantly to the perihematomal volume and exacerbates mass effect, ischemia and infarction of adjacent structures $[5,24]$. Although cerebral edema's relation to neurological deficit and outcome after ICH remains controversial, it has served as a target for numerous candidate therapies $[8,25-27]$. ICH-associated cerebral ede$\mathrm{ma}$ is primarily vasogenic and develops in the PHZ [8]. Cerebral edema develops immediately after ICH onset, peaks in the next 5-6 days and lasts up to 2 weeks [8]. Edema formation occurs in 3 phases. During the acute phase (within the first few hours of onset), hydrostatic pressure and clot retraction cause clot-derived serum to move into the PHZ. Subacute (within 2 days of ICH) activation of the coagulation cascade and release of thrombin contributes to cerebral edema development. This is further worsened by the erythrocyte lysis and hemoglobin $(\mathrm{Hb})$ toxicity taking place primarily during the later stages [28]. The BBB disruption, induced by thrombin, MMPs, complement proteins and hemolytic byproducts, manifests $8-12 \mathrm{~h}$ after ICH onset and is also implicated in cerebral edema formation $[9,8,29]$.

Cellular damage or death, particularly of neurons, is another critical endpoint of ICH-induced secondary injuries [30] (fig. 1). Several interconnected molecular and cellular pathways lead to further neuronal injuries, necrosis or apoptosis following ICH [31]. Thrombin, a major contributor to edema formation and BBB damage, is involved in early brain injury [31]. Hb and its degradation products, such as heme, are released after erythrocyte lysis and mediate direct neuronal toxicity and death [30]. Infiltrating inflammatory cells, such as macrophages and neutrophils, aggravate the ongoing injury partly through production of cytokines, chemokines and reactive oxygen species [32]. Activated microglia and concurrent astrogliosis are also implicated in inflammatory cellular damages [33]. Activation of the complement cascade further heightens the inflammatory response, induces erythrocyte lysis to release $\mathrm{Hb}$-related molecules and causes cellular death through the formation of membrane attack complexes [5]. Though deleterious, the inflammatory and complement pathways are also critical for hematoma absorption, cellular debris clearance and postictal recovery $[34,35]$.

Advances in Neuroprotective Strategies

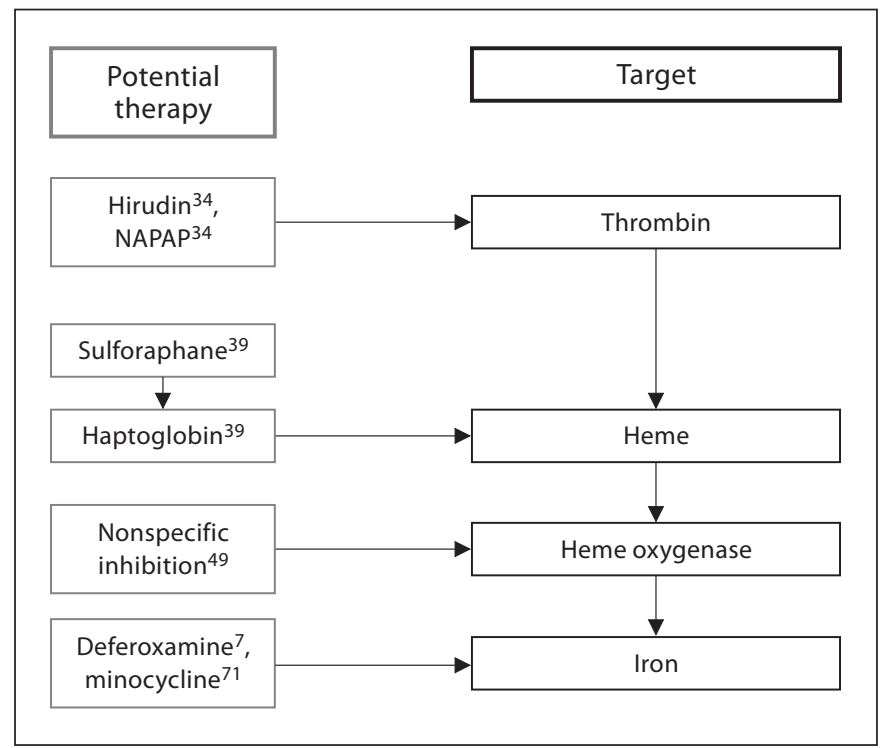

Fig. 2. Intracerebral-hematoma-derived products and potential therapies.

\section{Therapeutic Targets and Strategies}

\section{Hematoma-Derived Products}

Thrombin Inhibition

Thrombin is a serine protease and critical coagulation protein that is produced rapidly after ICH onset [36] (fig. 2). Thrombin is a key mediator in stopping the initial hemorrhage and preventing hematoma expansion [37]. At low concentrations, thrombin confers neuroprotective effect possibly through the upregulation of heat shock proteins and iron-handling proteins [38]. However, at high concentrations, as is usually the case in ICH, thrombin causes inflammatory cell infiltration, BBB breakdown, cerebral edema formation and neuronal death.

Hirudin and a-N-(2-naphthalenesulfonyl)-glycyl-(D)A-aminopheny-alanyl-piperidine (NAPAP), as thrombin inhibitors [39], have been shown to decrease cerebral edema in rat ICH models. Another thrombin inhibitor, argatroban, has recently been studied due to its ability to inhibit clot-bound thrombin, which is present in significant quantities in the hematoma [40]. Direct injection of argatroban $3 \mathrm{~h}$ after ICH significantly reduced the edema volume in animal models. Similarly, administration of high-dose systemic argatroban $6 \mathrm{~h}$ after ictus led to a significant reduction in cerebral edema. These data suggest that thrombin inhibitors may provide a potentially useful neuroprotective strategy.

Cerebrovasc Dis 2011;31:211-222 
Prevention of $\mathrm{Hb}$, Heme and Iron Toxicity

The release of $\mathrm{Hb}$ and other lysis products into the parenchyma can result in marked cerebral edema, brain injury and neurological deficits $[41,42]$. $\mathrm{Hb}$, in particular, is a powerful neurotoxin associated with cellular oxidative damage, necrosis and apoptosis [43]. Recently, haptoglobin (Hp) has been investigated as a potential neuroprotectant that can ameliorate the deleterious effects of $\mathrm{Hb}$ in $\mathrm{ICH}$ patients [44]. Hp is an acute-phase plasma protein that can form a stable complex with $\mathrm{Hb}$ to neutralize the cytotoxic and pro-oxidative properties of $\mathrm{Hb}$ and its byproducts [44]. The expression pattern of cerebral $\mathrm{Hp}$ closely mirrors the development of cytotoxic injury, cerebral edema and tissue damage after ICH. Furthermore, natural upregulation of $\mathrm{Hp}$ in the $\mathrm{PHZ}$ can significantly reduce cerebral injury in a rodent model [44]. Similar results were demonstrated when the local $\mathrm{Hp}$ levels were increased with systemic administration of sulforaphane [44]. Thus, Hp and its upregulators, such as sulforaphane, are promising neuroprotectants that are capable of attenuating $\mathrm{Hb}$-mediated cerebral injury after ICH (fig. 2).

Iron is released when heme is degraded by heme oxygenase $(\mathrm{HO})$ and can reach high concentrations in the brain after ICH [45]. ICH-associated iron accumulation begins as early as the first postbleed day and peaks in the coming week [46]. Iron is critical for normal cerebral functioning. However, iron overload can independently cause cerebral edema, worsen thrombin-induced edema [47] and induce neuronal damage through oxidative stress and excitotoxicity [48-50].

Studies have recently focused on $\mathrm{HO}$, the rate-limiting enzyme in the breakdown of heme, as a potential neuroprotective target. $\mathrm{HO}$ exists in 2 isoforms, $\mathrm{HO}-1$ and -2 , which primarily localize to neurons and microglia, respectively. In the normal brain, $\mathrm{HO}-2$ is the dominant form and accounts for the majority of the $\mathrm{HO}$-associated activities [51, 52]. At present, there are conflicting data regarding the role of $\mathrm{HO}$ in the setting of $\mathrm{ICH}$. Despite reports of HO-1 being neuroprotective, $\mathrm{HO}-1$ overexpression has been associated with $\mathrm{ICH}$-induced brain damage and its absence significantly decreased inflammatory cell infiltration, macrophage activation and oxidative DNA damage [22]. Studies have suggested that HO-2 may confer neuroprotection after ICH by either degrading heme or converting it to carbon monoxide and bilirubin. However, others have reported that the deletion of $\mathrm{HO}-2$ attenuates $\mathrm{Hb}$-induced neurotoxicity [53]. Nonspecific HO inhibitors such as tin-mesoporphyrin have been shown to reduce brain injury, suggesting that both isoforms may have predominantly deleterious effects following ICH [54].
Deferoxamine, an iron chelator, has also been shown to decrease production of hydroxyl radicals, activate compensatory transcription factors and ameliorate $\mathrm{Hb}$ associated neurotoxicity [7] (fig. 2). Deferoxamine may also attenuate cytotoxic edema formation through modulation of aquaporin- 4 channel expression [28]. Systemic administration of deferoxamine in ICH models reduced the severity of oxidative damage and cerebral edema, and also led to improved neurological and functional outcome $[55,56]$. Deferoxamine therapy in ICH patients has yielded evidence of decreased systemic oxidative stress [7]. Currently, deferoxamine is being investigated as a potential neuroprotectant for ICH patients in a phase I, multicenter, dose-finding, safety and feasibility study.

Upregulation of NF-Erythroid-2-Related Factor 2

NF-erythroid-2-related factor 2 (Nrf2) is a reductionoxidation-sensitive transcription factor that is activated by oxidative stress [57]. Nrf2 is thought to attenuate $\mathrm{Hb}$ and free radical species-mediated toxicity by inducing antioxidant genes, including $\mathrm{Hp}[43,58]$. Neurons from Nrf2-knockout mice are more vulnerable to oxidative stress than those of control animals, and transfection of Nrf2 restores reactive oxygen intermediate (ROI) resistance [59]. Furthermore, the knockout mice exhibit more perihematomal cellular DNA damage, apoptosis and neurological deficits as compared to controls after experimental ICH [60]. When Nrf2 was upregulated through the use of the upstream inducer sulforaphane in rats, there was a reduction in neutrophil migration, increase in ROI-detoxifying enzyme levels, and decrease in inflammation and oxidative damage after ICH [61].

\section{Inflammatory Pathways}

Cyclo-Oxygenase Inhibition

Cyclo-oxygenase (COX) is a key enzyme involved in the formation of prostanoids through the arachidonic acid pathway $[62,63]$. There are 3 isoforms, with COX-2 being the predominant isoform within the central nervous system, present in astrocytes, neurons and microglia [63]. COX-2 is highly inducible [64] and contributes to neuronal death in inflammatory settings [65]. In the setting of $\mathrm{ICH}, \mathrm{COX}$ upregulates the production of prostaglandins, prostacyclins and thromboxane, which in turn exacerbate the ongoing inflammation at the site of hematoma and the PHZ [66]. Studies have shown that celecoxib, a selective COX-2 inhibitor, reduces inflammation and brain edema in a dose-dependent manner in rats subjected to ICH [67]. Furthermore, celecoxib in conjunction with memantine, a noncompetitive NMDA re- 


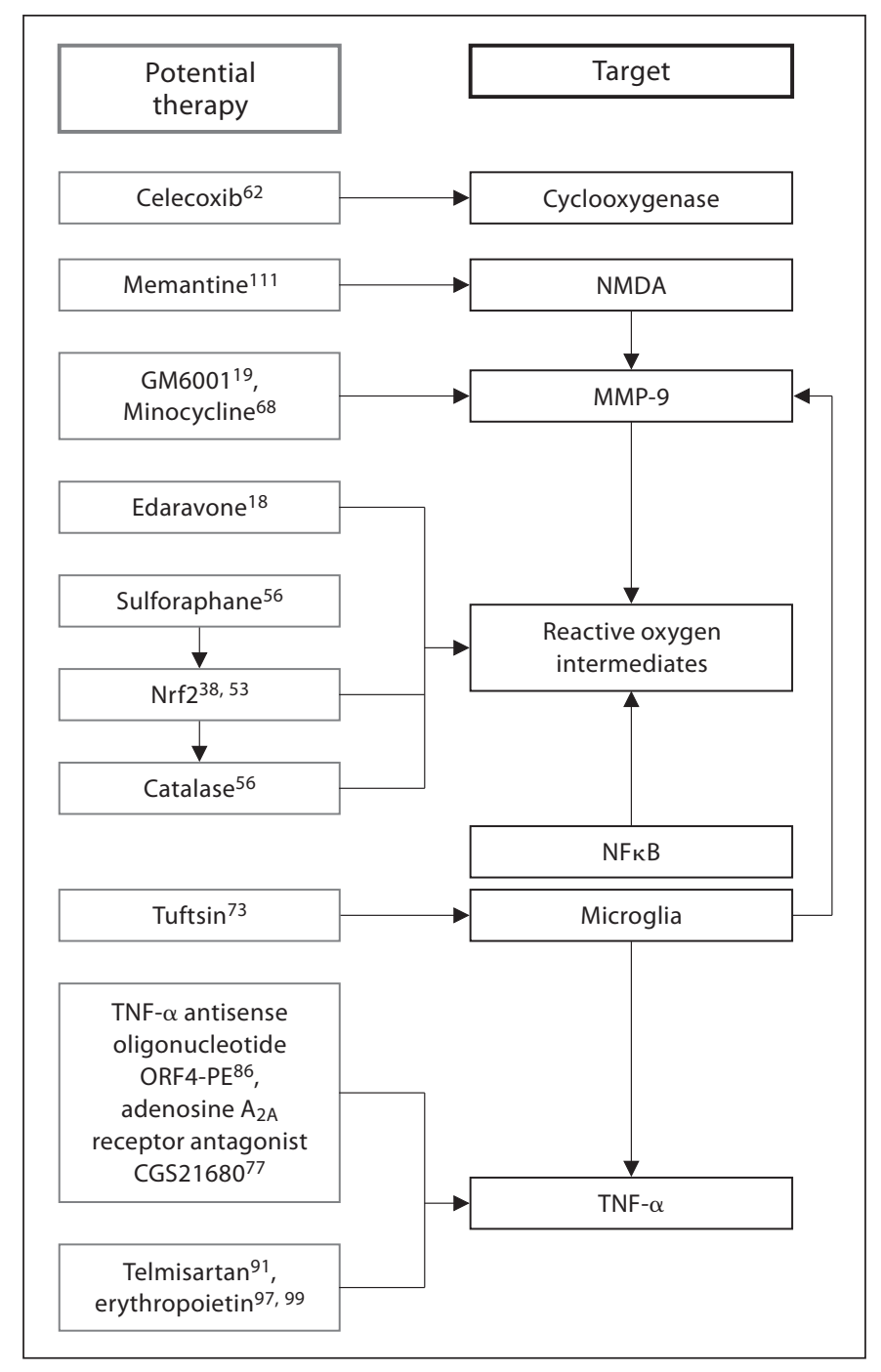

Fig. 3. Inflammatory pathway involved in intracerebral-hemorrhage-induced brain injury and potential therapeutic targets and agents. NFкB = Nuclear factor $\kappa$-light-chain-enhancer of activated $B$ cells; NMDA = N-methyl-D-aspartic acid; Nrf2 = nuclear factor erythroid 2-related factor; MMP-9 = matrix metalloproteinase-9; TNF- $\alpha=$ tumor necrosis factor- $\alpha$.

ceptor antagonist, worked synergistically to improve functional recovery in a rat ICH model (fig. 3) [16].

Targeting Matrix Metalloproteinases

MMPs are a family of zinc-dependent endopeptidases that play a critical role in the degradation and remodeling of extracellular matrix components [68]. These tightly regulated enzymes are implicated in an array of cellular functions and are involved in the inflammatory processes in various disease states $[68,69]$. Marked upregulation of MMPs is seen after ICH as a result of their activation by hematoma-derived products, such as plasma, thrombin and ROIs [68]. Thrombin and MMP-9, in particular, exacerbate neurotoxicity and death in human fetal neurons and mice by causing detachment of cellular integrin from the extracellular matrix [70]. GM-6001-mediated inhibition of MMP-9 led to reduction in neutrophil infiltration, oxidative stress, neurodegeneration and brain edema in a murine ICH model [20]. Furthermore, the free radical scavenger edaravone was able to reduce ROIinduced MMP upregulation, and the anti-inflammatory heat shock protein 70 inducer eranylgeranylacetone significantly lowered the MMP-9 expression levels and brain edema in rodent ICH models [71]. Furthermore, the tetracycline antibiotic minocycline also decreases the MMP-2 and -9 levels, reduces MMP-induced microvascular permeability shifts, BBB breakdown, inflammatory cell infiltration and iron-mediated neurotoxicity in cell cultures [72].

Inhibition of Inflammatory Cell Activation

Endogenous microglia become activated after ischemic conditions such as ICH and produce molecules such as interleukin- $1 \beta$ and tumor necrosis factor (TNF)- $\alpha$ that further inflammation in the hematoma site and the PHZ [73]. Tuftsin, a microglial inhibitor, reduces inflammatory cytokine release and attenuates brain edema [74]. Minocycline can also inhibit the microglia and modulate their activity in the setting of ICH [21].

Neutrophils are also involved in ICH-induced inflammatory injuries to the brain [75]. Inflammatory adhesion molecules become upregulated after ICH and lead to increased neutrophil infiltration into the site of hemorrhage and the PHZ [30]. CD18 on neutrophils allows interaction with the endothelium for extravasation, and its deletion results in reduction in cerebral edema after experimental ICH [76]. Selective adenosine $A_{2 A}$ receptor agonist, CGS 21680, which activates neutrophilic $\mathrm{A}_{2 \mathrm{~A}}$ receptors and blocks leukocytic adherence to the endothelium, also reduces neutrophil degranulation and ROI release $[77,78]$.

\section{TNF- $\alpha$ Modulation}

TNF- $\alpha$ is a proinflammatory cytokine that is strongly implicated in the pathophysiology of ICH-induced brain injury. TNF- $\alpha$ may cause secondary cerebral injuries through interference with astrocyte removal of extracellular glutamate, exacerbation of excitotoxicity, activation of microglia and induction of NFKB-driven production of inflammatory cytokines and ROIs [79]. Studies have 
also shown that the TNF- $\alpha$ levels directly correlate with the extent of brain damage following ICH [80].

Adenosine receptor agonists are potent inhibitors of TNF- $\alpha$ production, and adenosine $\mathrm{A}_{2 \mathrm{~A}}$ receptor agonist CGS 21680 decreases TNF- $\alpha$ production and neutrophil infiltration after experimental ICH [78]. Due to its short half-life and quick desensitization, other upstream targets are currently being explored [78]. One example is estrogen, which significantly increases $A_{2 A}$ receptor expression [81]. Another agent, ORF4-PE, is a TNF- $\alpha$ specific antisense oligodeoxynucleotide, and its intracerebral administration after ICH led to decrease in cell death and neurobehavioral deficits [82].

\section{AT1 Receptor Blockade}

Angiotensin II, a potent vasocontrictor hormone, has been implicated in inflammatory responses in neurologic conditions [83]. Angiotensin II also is involved in regulating nitric oxide synthase (NOS), and particularly endothelial NOS (eNOS), whose vasodilatory effect is important for preserving the cerebral blood flow and protecting against neuronal oxidative stress and excitotoxicity after ICH [84-86].

Potent angiotensin II receptor subtype AT1 blocker, telmisartan, has been shown to decrease inflammatory cell infiltration and edema volume after ICH induced in rats [87]. Additionally, it decreases the levels of inflammatory and proapoptotic molecules, including TNF- $\alpha$, Fas and FasL, upregulates eNOS expression, and decreases hemorrhage volume, edema, neutrophil infiltration and cellular apoptosis [87]. Telmisartan is also thought to function as a partial agonist of peroxisome proliferatoractivated receptor $\gamma$, which is critical for neutralizing free radical species and inhibiting the inflammatory cascade through decreased expression of the transcription factor, NFкB $[88,89]$. Due to their ability to target multiple pathways, telmisartan and other angiotensin II receptor subtype AT1 blockers may become particularly useful $\mathrm{ICH}$ neuroprotectants.

\section{Proapoptotic Pathways}

Valproic Acid

The anticonvulsant drug valproic acid (VPA) has recently become a focus of investigation as a neuroprotectant in ICH. VPA is thought to induce the extracellular signal-regulated kinase/cAMP response element-binding protein pathway to increase the expression of the antiapoptotic gene, bcl-2, after ICH [91]. VPA also increases the expression of heat shock protein 70 [92], which, as aforementioned, downregulates MMP-9, FasL and other

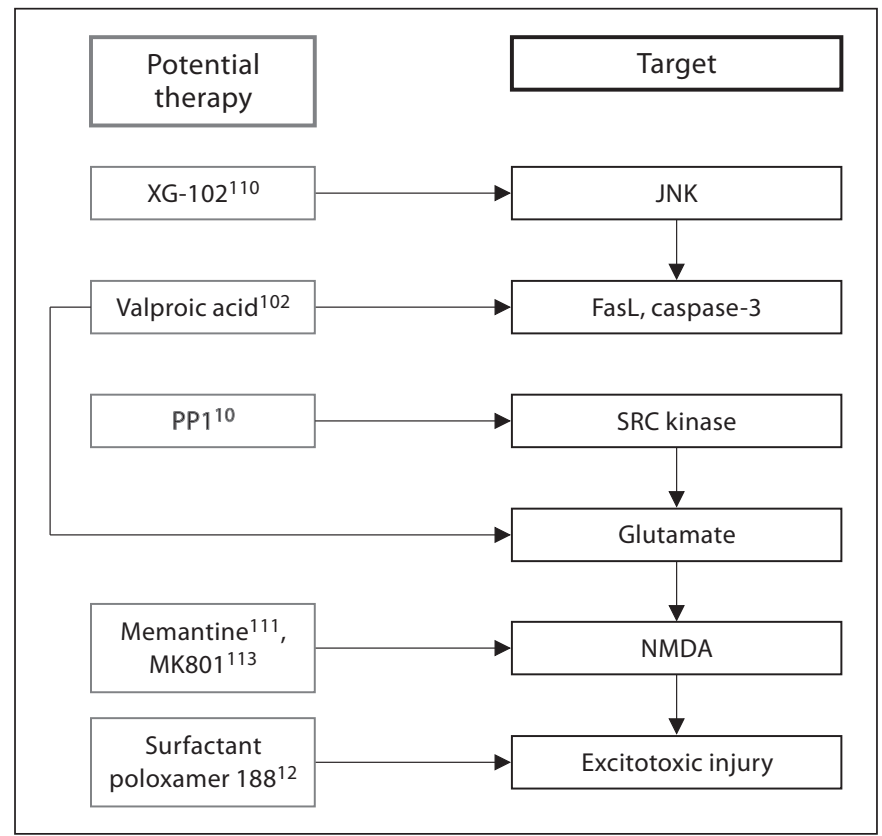

Fig. 4. Pro-apoptotic pathway involved in intracerebral hemorrhage-induced brain injury and potential therapeutic targets and agents. JNK = c-Jun N-terminal kinase; NMDA = N-methyl-Daspartic acid; PP1 = protein phosphatase 1 .

proinflammatory cytokines and confers antiapoptotic effects through the inhibition of caspase-3 activation [93]. Studies have demonstrated that VPA protects rat cortical neurons from glutamate-induced excitotoxicity [94] and increases the longevity of cultured cortical neurons. Furthermore, VPA has been shown to significantly limit hematoma expansion, reduce post-ICH upregulation in MMP-9 levels, and increase bcl-2 expression after experimental ICH (fig. 4) [95].

\section{Inhibition of c-Jun N-Terminal Kinase}

c-Jun N-terminal kinase (JNK) is a potent stress-activated kinase that mediates apoptosis in the setting of neurological insult $[96,97]$. It is thought that JNK is activated in neurons and microglia after ICH through the induction of stress receptors, such as apoptosis signaling kinase 1 and FasL receptors. Intravenous administration of XG102 , a selective inhibitor of JNK, into mice $3 \mathrm{~h}$ after ICH induction was associated with significant decrease in both edema and hematoma volume. In addition, XG-102treated animals had an improved neurological outcome $24 \mathrm{~h}$ after ictus [97]. XG-102 is also a mediator of inflammation and has been implicated in microglial activation and TNF- $\alpha$ upregulation [98]. Therefore, XG-102 and 
other JNK inhibitors may be useful neuroprotectants able to ameliorate both apoptosis and inflammation following ICH.

N-Methyl D-Aspartate/ $\alpha$-Amino-3-Hydroxyl-5-

Methyl-4-Isoxazole-Propionate Antagonism

The amino acid glutamate is the most predominant excitatory neurotransmitter in the central nervous system, but causes cellular dysfunction and apoptosis when pathologically released in large quantities [99]. Following $\mathrm{ICH}$, glutamate accumulates at the site of injury and binds to the $N$-methyl $\mathrm{D}$-aspartate (NMDA) and $\alpha$-amino-3-hydroxyl-5-methyl-4-isoxazole-propionate receptors, leading to massive elevation of intracellular calcium and decrease in intracellular adenosine-5'-triphosphate levels [100]. Glucose hypermetabolism also occurs, ultimately leading to the production of oxidative byproducts [101]. Toxicity is thought to be initiated by the thrombinmediated protease activated receptor-induced phosphorylation of the Src protein [102]. Src proteins enhance glutamate release from synaptic vesicles and potentiate NMDA receptors, thereby enhancing the neurotoxic calcium influx and free radical generation [103]. Targeting this pathway through molecular blockade has been shown to attenuate many of the aforementioned apoptotic and inflammatory effects. For instance, the Src kinase inhibitor, PP1, decreases pathologic glucose hypermetabolism and cell death after ICH [11]. The NMDA antagonist memantine also reduces hematoma expansion, and administration of its functional analog, MK801, has demonstrated a reduction in neurotoxicity, calcium overload and cerebral edema in porcine ICH models [104-106].

\section{Surfactant Poloxamer 188}

Surfactant poloxamer 188 is a novel neuroprotective approach in ICH. The compound is thought to facilitate membrane repair of damaged neurons, thereby leading to restoration of intracellular compartmentalization and preservation and recovery of cellular functions $[107,108]$. Poloxamer 188 protects cells against excitotoxic injury, possibly by intercalating into neuronal membranes and decreasing the rates of electrophysiological change after insult [107]. It also acts as an anti-inflammatory agent [109], decreasing macrophage infiltration and lipid peroxidation, as well as hematoma volume [13].

\section{Erythropoietin}

Erythropoietin (EPO) is a glycoprotein hormone that normally induces the differentiation of hematopoietic stem cells into erythrocytes via the BBB through abundant specific capillary receptors [110]. Evidence suggests that EPO is also an important modulator of various molecular cascades critical to cell functioning, survival and vascular responses, such as the STAT-3 and eNOS pathways, and it may prevent glutamate excitotoxicity, apoptosis and inflammation [110-113]. Recent work has suggested that EPO and its long-lasting analog, darbepoetin $\alpha$, bind the EPO receptor to exert neuroprotective and antiapoptotic effects through JAK-2- and Akt-dependent mechanisms [114].

\section{Discussion}

Neuroprotection constitutes a novel category of ICH therapy with sound biological rationale and significant potential for improving outcomes. Ongoing investigation continues to identify more effective therapeutic targets as well as optimal timing and methods for intervention. Nevertheless, ICH neuroprotection is an emerging field and there remain a number of challenges as it progresses towards becoming an effective treatment option in clinical settings.

Firstly, the development of neuroprotective strategies has been limited by incomplete understanding of ICH pathophysiology and mechanisms of secondary cerebral injuries. Although studies have implicated alterations in various molecular pathways and genetic expression patterns, the exact mechanisms of ICH-induced injuries and their association with outcome are incompletely understood $[31,115]$. For instance, the clinical significance of cerebral edema remains controversial. Rodent studies have suggested an association between reduced edema volume and improved functional outcome $[55,116,117]$. However, significant functional recovery can be achieved in the absence of edema reduction, suggesting that absolute edema volume does not independently predict outcome [118]. Furthermore, relative edema volume (edema volume/hematoma volume) has been shown to independently predict improved functional recovery following hyperacute spontaneous ICH (within $3 \mathrm{~h}$ after onset) without intraventricular extension; this suggests that hyperacute (within $24 \mathrm{~h}$ after onset) and delayed edemas aredistinctentitiesassociated withdifferent pathophysiology and outcome [17]. The current controversy underscores the need to better understand the mechanisms of edema formation as a dynamic process that is significantly affected by many factors, such as the etiology of ICH and time since onset $[17,119,120]$. Efforts should be 
made to elucidate the relationship between hyperacute and delayed edemas and the timing of edema volume measurement should be carefully noted when interpreting experimental results. In addition, it should be recognized that edema volume may be insufficient as a sole outcome measure to demonstrate potential clinical efficacy and it is becoming increasingly critical for neuroprotectants to show evidence for enhanced functional/ neurological outcome in addition to other outcome measures. Deferoxamine, celecoxib/memantine, ORF4-PE and XG-102 are such agents that are promising candidates for further investigation and initial efforts towards clinical translation.

Other aspects of ICH pathophysiology that require further investigation include the contribution of ischemia to edema formation and interactions among cerebral edema, perihematomal hypometabolic-hypoperfusion and cell death [38]. The mechanisms behind neuronal injuries leading to worse neurological outcome also need to be further defined. Timing of key molecular events and temporal alterations in their expression are still being worked out as well. Continued advances in the understanding of ICH will improve the therapeutic efficacies of neuroprotectants through more specific targeting and modulation of pathways of interest, coupled with optimal timing and degree of intervention.

Secondly, ICH-induced brain injuries result from complex interconnected molecular pathways, which furthers the need for neuroprotective strategies capable of attenuating multiple targets. This approach will better account for the heterogeneity of ICH pathophysiology and maximize the therapeutic benefits. Neuroprotectants such as XG-102 and sulforaphane are examples of agents that are capable of affecting different molecular pathologic pathways. Combination of neuroprotective agents may also allow synergistic effects on outcome, as demonstrated by the dual administration of celecoxib and memantine. Agents that confer protection on multiple cell types would also be useful as mounting evidence indicates that neuronal recovery and survival after $\mathrm{ICH}$ are strongly dependent on the status of surrounding nonneuronal cells [33]. Of note, many pathologic molecular pathways triggered after ICH may have beneficial roles at different time points during the clinical course. Examples include the hemostatic and neuroprotective properties of thrombin $[37,121]$ and the involvement of complement in hematoma absorption, cellular debris clearance and postictal neurogenesis $[5,35]$. Therefore, multitargeting agents and combination therapies should allow careful modulation of individual targets.
Thirdly, a majority of ICH neuroprotectants currently under investigation remain experimental and have yet to be tested in a clinical setting $[4,6]$. Furthermore, few clinical trials have been attempted to date, and none have been appropriately powered to detect significant clinical benefit. The bench-to-bedside translation of ICH neuroprotective strategies has been challenging largely due to the inherent differences between experimental and clinical ICHs [122]. Although animal models are highly useful for characterizing ICH-associated injuries and underlying mechanisms, they are ultimately insufficient and/or inaccurate representations of human ICH [4]. The rodent intrastriatal autologous blood injection model [123] is widely used but has been limited by its inability to reproduce spontaneous or ongoing bleeding [122]. The bacterial collagenase injection model [124], which is another commonly used method, has been associated with heightened collagenase-induced inflammatory response and neurotoxicity [122]. The 2 models may also differ with regard to their reproducibility, location and degree of structural injury, characteristics of neurological impairment and recovery, and optimal neurological assessment method [122]. Moreover, both methods involve anesthesia and invasive anatomical access, which may alter the molecular environment and treatment response in an uncontrolled manner $[4,8]$. In the absence of a model that perfectly mimics human $\mathrm{ICH}$, rigorous, comprehensive and longterm assessment of outcome should proceed with the best available ICH models. Furthermore, cautious interpretation of the existing data, thorough understanding of each model's strengths and limitations, and insight into the precise differences between experimental and human ICHs will be critical to successful clinical trials.

A number of well-designed trials have recently begun, including the Dose Finding and Safety Study of Deferoxamine in Patients with Brain Hemorrhage, Administration of Celecoxib for Treatment of Intracerebral Hemorrhage, Safety of Pioglitazone for Hematoma Resolution in Intracerebral Hemorrhage and Intravenous Tauroursodeoxycholic Acid trials. Many of these trials have incorporated lessons learned from the previous neuroprotection trials in ischemic stroke and represent an important progress in ICH neuroprotection research. Ongoing efforts towards meticulous consideration of trial design, outcome measures, optimal timing of intervention and heterogeneity among study subjects will significantly expedite the much-anticipated clinical translation of ICH neuroprotection. 


\section{Conclusion}

As neuroprotective strategies move from bench to bedside, they hold the potential to become an important treatment option for ICH. Increasing insight into the pathophysiology of ICH-induced cerebral injuries will continue to aid the development and refinement of neuroprotective strategies. Furthermore, improved under- standing and application of experimental models will enhance the clinical translation of results and contribute to successful randomized clinical trials. In the future, neuroprotection will likely contribute to multimodality managements, along with intensive care and surgical treatments, to optimize the extent of clot removal, increase neuronal survival and improve clinical outcomes after ICH.

\section{References}

1 Kase CS: Intracerebral haemorrhage. Baillieres Clin Neurol 1995;4:247-278.

2 Anderson CS: Medical management of acute intracerebral hemorrhage: Curr Opin Crit Care 2009;15:93-98.

-3 Chuang Y-C, Chen Y-M, Peng S-K, Peng S-Y: Risk stratification for predicting 30-day mortality of intracerebral hemorrhage. Int J Qual Health Care 2009;21:441-447.

-4 Qureshi AI, Mendelow AD, Hanley DF: Intracerebral haemorrhage. Lancet 2009;373: 1632-1644.

5 Ducruet AF, Zacharia BE, Hickman ZL, Grobelny BT, Yeh ML, Sosunov SA Jr: ESC: the complement cascade as a therapeutic target in intracerebral hemorrhage. Exp Neurol 2009;219:398-403.

6 Lapchak PA, Araujo DM: Advances in hemorrhagic stroke therapy: conventional and novel approaches. Expert Opin Emerg Drugs 2007;12:389-406.

7 Selim M: Deferoxamine mesylate: a new hope for intracerebral hemorrhage: from bench to clinical trials. Stroke 2009;40:S90S91.

-8 Xi G, Keep RF, Hoff JT: Mechanisms of brain injury after intracerebral haemorrhage. Lancet Neurol 2006;5:53-63.

-9 Lee KR, Kawai N, Kim S, Sagher O, Hoff JT: Mechanisms of edema formation after intracerebral hemorrhage: effects of thrombin on cerebral blood flow, blood-brain barrier permeability, and cell survival in a rat model. J Neurosurg 1997;86:272-278.

10 Hurtado O, Pradillo JM, Alonso-Escolano D, Lorenzo P, Sobrino T, Castillo J, Lizasoain I, Moro MA: Neurorepair versus neuroprotection in stroke. Cerebrovasc Dis 2006;21 (suppl 2):54-63.

-11 Ardizzone TD, Zhan X, Ander BP, Sharp FR: Src kinase inhibition improves acute outcomes after experimental intracerebral hemorrhage. Stroke 2007;38:1621-1625.

-12 Mayer SA, Rincon F: Treatment of intracerebral haemorrhage. Lancet Neurol 2005;4: 662-672.
13 Cadichon SB, Le Hoang M, Wright DA, Curry DJ, Kang U, Frim DM: Neuroprotective effect of the surfactant poloxamer 188 in a model of intracranial hemorrhage in rats. Neurosurg 2007;106:36-40.

14 Sinn DI, Lee ST, Chu K, Jung KH, Kim EH, Kim JM, Park DK, Song EC, Kim BS, Yoon SS, Kim M, Roh JK: Proteasomal inhibition in intracerebral hemorrhage: neuroprotective and anti-inflammatory effects of bortezomib. Neurosci Res 2007;58:12-18.

15 Seyfried D, Han Y, Lu D, Chen J, Bydon A, Chopp M: Improvement in neurological outcome after administration of atorvastatin following experimental intracerebral hemorrhage in rats. J Neurosurg 2004;101:104107.

16 Sinn D-I, Lee S-T, Chu K, Jung K-H, Song E-C, Kim J-M, Park D-K, Kim M, Roh J-K: Combined neuroprotective effects of celecoxib and memantine in experimental intracerebral hemorrhage. Neurosci Lett 2007; 411:238-242.

17 Keep RF, Xi G, Hua Y, Hoff JT: The deleterious or beneficial effects of different agents in intracerebral hemorrhage: think big, think small, or is hematoma size important? Stroke 2005;36:1594-1596.

18 Gebel JM, Jauch EC, Brott TG, Khoury J, Sauerbeck L, Salisbury S, Spilker J, Tomsick TA, Duldner J, Broderick JP: Relative edema volume is a predictor of outcome in patients with hyperacute spontaneous intracerebral hemorrhage. Stroke 2002;33:2636-2641.

19 Yagi K, Kitazato KT, Uno M, Tada Y, Kinouchi T, Shimada K, Nagahiro S: Edaravone, a free radical scavenger, inhibits MMP-9-related brain hemorrhage in rats treated with tissue plasminogen activator. Stroke 2009; 40:626-631.

20 Wang J, Tsirka SE: Neuroprotection by inhibition of matrix metalloproteinases in a mouse model of intracerebral haemorrhage. Brain 2005; 128:1622-1633.

21 Yenari MA, Xu L, Tang XN, Qiao Y, Giffard RG: Microglia potentiate damage to bloodbrain barrier constituents: improvement by minocycline in vivo and in vitro. Stroke 2006;37:1087-1093.
22 Wang Q, Tang XN, Yenari MA: The inflammatory response in stroke. J Neuroimmunol 2007; 184:53-68.

23 Skidmore C, Andrefsky J: Spontaneous intracerebral hemorrhage: epidemiology, pathophysiology, and medical management. Neurosurg Clin North Am 2002;13:281-288.

24 Thiex R, Tsirka SE: Brain edema after intracerebral hemorrhage: mechanisms, treatment options, management strategies, and operative indications. Neurosurg Focus 2007;22:E6.

25 Tomita H, Ito U, Ohno K, Hirakawa K: Chronological changes in brain edema induced by experimental intracerebral hematoma in cats. Acta Neurochir Suppl (Wien) 1994;60:558-560.

26 Sansing LH, Kaznatcheeva EA, Perkins CJ, Komaroff E, Gutman FB, Newman GC: Edema after intracerebral hemorrhage: correlations with coagulation parameters and treatment. J Neurosurg 2003;98:985-992.

-27 Arima H, Wang JG, Huang Y, Heeley E, Skulina C, Parsons MW, Peng B, Li Q, Su S, Tao QL, Li YC, Jiang JD, Tai LW, Zhang JL, Xu E, Cheng Y, Morgenstern LB, Chalmers J, Anderson CS: Significance of perihematomal edema in acute intracerebral hemorrhage: the interact trial. Neurology 2009;73:19631968.

28 Qing WG, Dong YQ, Ping TQ, Lai LG, Fang LD, Min HW, Xia L, Heng PY: Brain edema after intracerebral hemorrhage in rats: the role of iron overload and aquaporin 4 . J Neurosurg 2009;110:462-468.

29 Xue M, Yong VW: Matrix metalloproteinases in intracerebral hemorrhage. Neurol Res 2008;30:775-782.

30 Wang J, Doré S: Inflammation after intracerebral hemorrhage. J Cereb Blood Flow Metab 2007;27:894-908.

-31 Sharp F, Liu DZ, Zhan X, Ander BP: Intracerebral hemorrhage injury mechanisms: glutamate neurotoxicity, thrombin, and Src. Acta Neurochir Suppl 2008;105:43-46.

32 Aronowski J, Hall CE: New horizons for primary intracerebral hemorrhage treatment: experience from preclinical studies. Neurol Res 2005;27:268-279. 
33 Wasserman JK, Yang H, Schlichter LC: Glial responses, neuron death and lesion resolution after intracerebral hemorrhage in young vs. aged rats. Eur J Neurosci 2008;28:13161328.

-34 Arumugam T, Woodruff T, Lathia J, Selvaraj P, Mattson M, Taylor S: Neuroprotection in stroke by complement inhibition and immunoglobulin therapy. Neuroscience 2009;158: 1074-1089.

-35 Rahpeymai Y, Hietala MA, Wilhelmsson U, Fotheringham A, Davies I, Nilsson AK, Zwirner J, Wetsel RA, Gerard C, Pekny M, Pekna M: Complement: a novel factor in basal and ischemia-induced neurogenesis. EMBO J 2006;25:1364-1374.

>36 Hua Y, Keep RF, Hoff JT, Xi G: Brain injury after intracerebral hemorrhage: the role of thrombin and iron. Stroke 2007;38:759-762.

>37 Hua Y, Keep RF, Hoff JT, Xi G: Thrombin preconditioning attenuates brain edema induced by erythrocytes and iron. J Cereb Blood Flow Metab 2003;23:1448-1454.

-38 Hua Y, Keep R, Hoff J, Xi G: Brain injury after intracerebral hemorrhage: the role of thrombin and iron. Stroke 2007;38:759.

-39 Schaden E, Kozek-Langenecker SA: Direct thrombin inhibitors: pharmacology and application in intensive care medicine. Intensive Care Med 2010;36:1127-1137.

-40 Kitaoka T, Hua Y, Xi G, Hoff JT, Keep RF: Delayed argatroban treatment reduces edema in a rat model of intracerebral hemorrhage. Stroke 2002;33:3012-3018.

-41 Wu G, Xi G, Huang F: Spontaneous intracerebral hemorrhage in humans: hematoma enlargement, clot lysis, and brain edema. Acta Neurochir Suppl 2006;96:78-80.

-42 XiG, Keep RF, Hoff JT: Erythrocytes and delayed brain edema formation following intracerebral hemorrhage in rats. J Neurosurg 1998;89:991-996.

43 Zhao X, Song S, Sun G, Strong R, Zhang J, Grotta JC, Aronowski J: Neuroprotective role of haptoglobin after intracerebral hemorrhage. J Neurosci 2009;29:15819-15827.

44 Zhao X, Song S, Sun G, Strong R, Zhang J, Grotta JC, Aronowski J: Neuroprotective role of haptoglobin after intracerebral hemorrhage. J Neurosci 2009;29:15819-15827.

-45 Wu J, Hua Y, Keep RF, Nakamura T, Hoff JT, $\mathrm{Xi} \mathrm{G}$ : Iron and iron-handling proteins in the brain after intracerebral hemorrhage. Stroke 2003;34:2964-2969.

46 Qing WG, Dong YQ, Ping TQ, Lai LG, Fang LD, Min HW, Xia L, Heng PY: Brain edema after intracerebral hemorrhage in rats: the role of iron overload and aquaporin 4 . J Neurosurg 2009;110:462-468.

-47 Huang FP, Xi G, Keep RF, Hua Y, Nemoianu A, Hoff JT: Brain edema after experimental intracerebral hemorrhage: role of hemoglobin degradation products. J Neurosurg 2002; 96:287-293.
48 Wagner KR, Sharp FR, Ardizzone TD, Lu A, Clark JF: Heme and iron metabolism: role in cerebral hemorrhage. J Cereb Blood Flow Metab 2003;23:629-652.

-49 Regan RF, Panter SS: Hemoglobin potentiates excitotoxic injury in cortical cell culture. J Neurotrauma 1996;13:223-231.

50 Goldstein L, Teng ZP, Zeserson E, Patel M, Regan RF: Hemin induces an iron-dependent, oxidative injury to human neuron-like cells. J Neurosci Res 2003;73:113-121.

51 Wang J, Zhuang H, Doré S: Heme oxygenase 2 is neuroprotective against intracerebral hemorrhage. Neurobiol Dis 2006;22:473476.

52 Chang EF, Wong RJ, Vreman HJ, Igarashi T, Galo E, Sharp FR, Stevenson DK, NobleHaeusslein LJ: Heme oxygenase-2 protects against lipid peroxidation-mediated cell loss and impaired motor recovery after traumatic brain injury. J Neurosci 2003;23:36893696.

53 Qu Y, Chen J, Benvenisti-Zarom L, Ma X, Regan RF: Effect of targeted deletion of the heme oxygenase-2 gene on hemoglobin toxicity in the striatum. J Cereb Blood Flow Metab 2005;25:1466-1475.

54 Wagner KR, Hua Y, de Courten-Myers GM, Broderick JP, Nishimura RN, Lu SY, Dwyer BE: Tin-mesoporphyrin, a potent heme oxygenase inhibitor, for treatment of intracerebral hemorrhage: in vivo and in vitro studies. Cell Mol Biol (Noisy-le-grand) 2000;46:597608.

55 Nakamura T, Keep RF, Hua Y, Schallert T, Hoff JT, Xi G: Deferoxamine-induced attenuation of brain edema and neurological deficits in a rat model of intracerebral hemorrhage. Neurosurg Focus 2003;15:ECP4.

56 Okauchi M, Hua Y, Keep RF, Morgenstern LB, Schallert T, Xi G: Deferoxamine treatment for intracerebral hemorrhage in aged rats: therapeutic time window and optimal duration. Stroke 2010;41:375-382.

57 Lee JM, Li J, Johnson DA, Stein TD, Kraft AD, Calkins MJ, Jakel RJ, Johnson JA: Nrf2, a multi-organ protector? FASEB J 2005; 19 : 1061-1066.

58 Kensler TW, Wakabayashi N, Biswal S: Cell survival responses to environmental stresses via the keap1-nrf2-are pathway. Annu Rev Pharmacol Toxicol 2006;47:89-116

59 Zhao J, Moore AN, Redell JB, Dash PK: Enhancing expression of nrf2-driven genes protects the blood brain barrier after brain injury. J Neurosci 2007;27:10240-10248.

60 Wang J, Fields J, Zhao C, Langer J, Thimmulappa RK, Kensler TW, Yamamoto M, Biswal S, Doré S: Role of nrf2 in protection against intracerebral hemorrhage injury in mice. Free Radic Biol Med 2007;43:408-414.

61 Zhao X, Sun G, Zhang J, Strong R, Dash PK, Kan YW, Grotta JC, Aronowski J: Transcription factor nrf2 protects the brain from damage produced by intracerebral hemorrhage. Stroke 2007;38:3280-3286.
62 Fitzgerald GA, Patrono C: The coxibs, selective inhibitors of cyclooxygenase-2. N Engl J Med 2001;345:443-442.

63 Graham SH, Hickey RW: Cyclooxygenases in central nervous system diseases: a special role for cyclooxygenase 2 in neuronal cell death. Arch Neurol 2003;60:628-630.

64 Drachman DB, Frank K, Dykes-Hoberg M, Teismann P, Almert G, Przedborski S, Rothstein JD: Cyclooxygenase 2 inhibition protects motor neurons and prolongs survival in a transgenic mouse model of ALS. Ann Neurol 2002;52:771-778.

65 Iadecola C: Cyclooxygenase-2 and stroke: the long and the short of it. Ann Neurol 2003; 54:141-142.

66 Bryzgina TM, Aleksiuk LI, Martynova TV, Sukhina VS, Aleksieieva IM: Effect of inhibitors of cyclooxygenase and lipoxygenase pathways of arachidonic acid oxidation on the immune response and the activity of the monoxygenase system and lipid peroxidation in the spleen and liver in mice. Fiziol $\mathrm{Zh}$ 2001;47:46-52.

67 Chu K, Jeong S-W, Jung K-H, Han S-Y, Lee S-T, Kim M, Roh J-K: Celecoxib induces functional recovery after intracerebral hemorrhage with reduction of brain edema and perihematomal cell death. J Cereb Blood Flow Metab 2004;24:926-933.

68 Rosenberg GA: Matrix metalloproteinases in neuroinflammation. Glia 2002;39:279291.

-69 Yong VW, Power C, Forsyth P, Edwards DR: Metalloproteinases in biology and pathology of the nervous system. Nat Rev Neurosci 2001;2:502-511.

70 Giancotti F, Ruoslahti E: Integrin signaling. Science 1999;285:1028-1032.

71 Sinn D-I, Chu K, Lee S-T, Song E-C, Jung K-H, Kim E-H, Park D-K, Kang K-M, Kim $\mathrm{M}$, Roh J-K: Pharmacological induction of heat shock protein exerts neuroprotective effects in experimental intracerebral hemorrhage. Brain Res 2007;1135:167-176.

72 Chen-Roetling J, Chen L, Regan RF: Minocycline attenuates iron neurotoxicity in cortical cell cultures. Biochem Biophys Res Commun 2009;386:322-326.

73 Morioka T, Kalehua AN, Streit WJ: Characterization of microglial reaction after middle cerebral artery occlusion in rat brain. J Comp Neurol 1993;327:123-132.

74 Wang J, Tsirka SE: Tuftsin fragment $1-3$ is beneficial when delivered after the induction of intracerebral hemorrhage. Stroke 2005;36: 613-618.

75 Garrett MC, Otten ML, Starke RM, Komotar RJ, Magotti P, Lambris JD, Rynkowski MA, Connolly ES: Synergistic neuroprotective effects of c $3 a$ and c5a receptor blockade following intracerebral hemorrhage. Brain Res 2009;1298:171-177. 
76 Titova E, Ostrowski RP, Kevil CG, Tong W, Rojas H, Sowers LC, Zhang JH, Tang J: Reduced brain injury in cd18-deficient mice after experimental intracerebral hemorrhage. J Neurosci Res 2008;86:3240-3245.

-77 Revan S, Montesinos MC, Naime D, Landau $\mathrm{S}$, Cronstein BN: Adenosine a2 receptor occupancy regulates stimulated neutrophil function via activation of a serine/threonine protein phosphatase. J Biol Chem 1996;271: 17114-17118.

-78 Mayne M, Fotheringham J, Yan HJ, Power C, Del Bigio MR, Peeling J, Geiger JD: Adenosine a2a receptor activation reduces proinflammatory events and decreases cell death following intracerebral hemorrhage. Ann Neurol 2001;49:727-735.

79 Schütze S, Wiegmann K, Machleidt T, Krönke M: TNF-induced activation of NF- $к \mathrm{~b}$. Immunobiology 1995;193:193-203.

-80 Mathiesen T, Edner G, Ulfarsson E, Andersson B: Cerebrospinal fluid interleukin-1 receptor antagonist and tumor necrosis factor$\alpha$ following subarachnoid hemorrhage. J Neurosurg 1997;87:215-220.

-81 Lin C-L, Dumont AS, Tsai Y-J, Huang J-H, Chang KP, Kwan AL, Hong YR, Howng SL: $17 \beta$-estradiol activates adenosine a $2 \mathrm{a}$ receptor after subarachnoid hemorrhage. J Surg Res 2009; 157:208-215.

-82 Mayne M, Ni W, Yan HJ, Xue M, Johnston JB, Del Bigio MR, Peeling J, Power C: Antisense oligodeoxynucleotide inhibition of tumor necrosis factor- $\alpha$ expression is neuroprotective after intracerebral hemorrhage. Stroke 2001;32:240-248

83 Walther T, Olah L, Harms C, Maul B, Bader M, Hörtnagl H, Schultheiss H-P, Mies G: Ischemic injury in experimental stroke depends on angiotensin II. FASEB J 2002;16: 169-176.

-84 Agnoletti L, Curello S, Bachetti T, Malacarne F, Gaia G, Comini L, Volterrani M, Bonetti P, Parrinello G, Cadei M, Grigolato PG, Ferrari R: Serum from patients with severe heart failure downregulates eNOS and is proapoptotic: role of tumor necrosis factor- $\alpha$. Circulation 1999;100:1983-1991.

-85 Endres M, Laufs U, Liao JK, Moskowitz MA: Targeting eNOS for stroke protection. Trends Neurosci 2004;27:283-289.

-86 Iadecola C: Bright and dark sides of nitric oxide in ischemic brain injury. Trends Neurosci 1997;20:132-139.

-87 Jung K-H, Chu K, Lee S-T, Kim S-J, Song E-C, Kim E-H, Park D-K, Sinn D-I, Kim J-M, Kim $\mathrm{M}$, Roh J-K: Blockade of AT1 receptor reduces apoptosis, inflammation, and oxidative stress in normotensive rats with intracerebral hemorrhage. J Pharmacol Exp Ther 2007;322:1051-1058.
88 Zhao CY, Wang JB, Deng ZJ, Liu JW, Li JM, Li L, Jiang LL: Relationship between NF- $\mathrm{b}$ binding activity and expression of PPAR $\gamma$ mRNA in the livers of rats with fatty liver disease. Zhonghua Gan Zang Bing Za Zhi 2005;13:96-100

89 Kawakami M, Sekiguchi M, Sato K, Kozaki S, Takahashi M: Erythropoietin receptormediated inhibition of exocytotic glutamate release confers neuroprotection during chemical ischemia. J Biol Chem 2001;276: 39469-39475.

90 Benson SC, Pershadsingh HA, Ho CI, Chittiboyina A, Desai P, Pravenec M, Qi N, Wang J, Avery MA, Kurtz TW: Identification of telmisartan as a unique angiotensin II receptor antagonist with selective PPAR $\gamma$-modulating activity. Hypertension 2004;43:9931002.

-91 Creson TK, Yuan P, Manji HK, Chen G: Evidence for involvement of ERK, PI3K, and RSK in induction of Bcl-2 by valproate. J Mol Neurosci 2009;37:123-134.

$\$ 92$ Pan T, Li X, Xie W, Jankovic J, Le W: Valproic acid-mediated Hsp70 induction and anti-apoptotic neuroprotection in SH-SY5Y cells. FEBS Lett 2005;579:6716-6720.

93 Pandey P, Farber R, Nakazawa A, Kumar S, Bharti A, Nalin C, Weichselbaum R, Kufe D, Kharbanda S: Hsp27 functions as a negative regulator of cytochrome $\mathrm{C}$-dependent activation of procaspase-3. Oncogene 2000;19: 1975-1981.

94 Hashimoto R, Hough C, Nakazawa T, Yamamoto T, Chuang D-M: Lithium protection against glutamate excitotoxicity in rat cerebral cortical neurons: involvement of NMDA receptor inhibition possibly by decreasing NR2B tyrosine phosphorylation. J Neurochem 2002;80:589-597.

$\checkmark 95$ Sinn D-I, Kim S-J, Chu K, Jung K-H, Lee S-T, Song E-C, Kim J-M, Park D-K, Kun Lee S, Kim M, Roh J-K: Valproic acid-mediated neuroprotection in intracerebral hemorrhage via histone deacetylase inhibition and transcriptional activation. Neurobiol Dis 2007;26:464-472.

$>96$ Wiegler K, Bonny C, Coquoz D, Hirt L: The JNK inhibitor XG-102 protects from ischemic damage with delayed intravenous administration also in the presence of recombinant tissue plasminogen activator. Cerebrovasc Dis 2008;26:360-366.

$\checkmark 97$ Michel-Monigadon D, Bonny C, Hirt L: cJun N-terminal kinase pathway inhibition in intracerebral hemorrhage. Cerebrovasc Dis 2010;29:564-570.

98 Palin K, McCusker RH, Strle K, Moos F, Dantzer R, Kelley KW: Tumor necrosis factor- $\alpha$-induced sickness behavior is impaired by central administration of an inhibitor of c-Jun N-terminal kinase. Psychopharmacology (Berl) 2008;197:629-635.

$\checkmark 99$ Lipton S, Chen HS: Paradigm shift in neuroprotective drug development: Clinically tolerated nMDA receptor inhibition by memantine. Cell Death Differ 2004;11:18-20.
100 Noch E, Khalili K: Molecular mechanisms of necrosis in glioblastoma: the role of glutamate excitotoxicity. Cancer Biol Ther 2009;8:1791-1797.

101 Ardizzone TD, Lu A, Wagner KR, Tang Y, Ran R, Sharp FR: Glutamate receptor blockade attenuates glucose hypermetabolism in perihematomal brain after experimental intracerebral hemorrhage in rat. Stroke 2004;35:2587-2591.

102 Wang S-J: A role for Src kinase in the regulation of glutamate release from rat cerebrocortical nerve terminals. Neuroreport 2003;14:1519-1522.

103 Liu Y, Zhang G, Gao C, Hou X: NMDA receptor activation results in tyrosine phosphorylation of NMDA receptor subunit $2 \mathrm{~A}(\mathrm{NR} 2 \mathrm{~A})$ and interaction of PYK 2 and Src with NR2A after transient cerebral ischemia and reperfusion. Brain Res 2001;909: 51-58.

104 Thiex R, Weis J, Krings T, Barreiro S, Yakisikli-Alemi F, Gilsbach JM, Rohde V: Addition of intravenous N-methyl-D-aspartate receptor antagonists to local fibrinolytic therapy for the optimal treatment of experimental intracerebral hemorrhages. J Neurosurg 2007;106:314-320.

105 Lee S-T, Chu K, Jung K-H, Kim J, Kim E-H, Kim S-J, Sinn D-I, Ko S-Y, Kim M, Roh J-K: Memantine reduces hematoma expansion in experimental intracerebral hemorrhage, resulting in functional improvement. J Cereb Blood Flow Metab 2006;26:536-544.

106 Kaur J, Zhao Z, Klein GM, Lo EH, Buchan AM: The neurotoxicity of tissue plasminogen activator? J Cereb Blood Flow Metab 2004;24:945-963.

107 Maskarinec SA, Hannig J, Lee RC, Lee KYC: Direct observation of poloxamer 188 insertion into lipid monolayers. Biophys J 2002;82:1453-1459.

108 Marks JD, Pan CY, Bushell T, Cromie W, Lee RC: Amphiphilic, tri-block copolymers provide potent membrane-targeted neuroprotection. FASEB J 2001;15:1107-1109.

109 Curry DJ, Wright DA, Lee RC, Kang UJ, Frim DM: Poloxamer 188 volumetrically decreases neuronal loss in the rat in a timedependent manner. Neurosurgery 2004;55: 943-948; discussion 948-949.

110 Brines ML, Ghezzi P, Keenan S, Agnello D, de Lanerolle NC, Cerami C, Itri LM, Cerami A: Erythropoietin crosses the bloodbrain barrier to protect against experimental brain injury. Proc Natl Acad Sci USA 2000;97:10526-10531

111 Sasaki R: Pleiotropic functions of erythropoietin. Intern Med 2003;42:142-149.

112 Lee S-T, Chu K, Sinn D-I, Jung K-H, Kim E-H, Kim S-J, Kim J-M, Ko S-Y, Kim M, Roh J-K: Erythropoietin reduces perihematomal inflammation and cell death with eNOS and STAT3 activations in experimental intracerebral hemorrhage. J Neurochem 2006;96:1728-1739. 
113 Celik M, Gokmen N, Erbayraktar S, Akhisaroglu M, Konakc S, Ulukus C, Genc S, Genc K, Sagiroglu E, Cerami A, Brines M: Erythropoietin prevents motor neuron apoptosis and neurologic disability in experimental spinal cord ischemic injury. Proc Natl Acad Sci USA 2002;99:22582263.

114 Grasso G, Graziano F, Sfacteria A, Carletti F, Meli F, Maugeri R, Passalacqua M, Certo F, Fazio M, Buemi M, Iacopino DG: Neuroprotective effect of erythropoietin and darbepoetin $\alpha$ after experimental intracerebral hemorrhage. Neurosurgery 2009;65: 763-769; discussion 769-770.

115 Lu A, Tang Y, Ran R, Ardizzone TL, Wagner KR, Sharp FR: Brain genomics of intracerebral hemorrhage. J Cereb Blood Flow Metab 2006;26:230-252.
116 Gong Y, Hua Y, Keep RF, Hoff JT, Xi G: Intracerebral hemorrhage: effects of aging on brain edema and neurological deficits. Stroke 2004;35:2571-2575.

117 Thiex R, Mayfrank L, Rohde V, Gilsbach JM, Tsirka SA: The role of endogenous versus exogenous TPA on edema formation in murine ICH. Exp Neurol 2004;189:25-32.

118 Arima H, Wang JG, Huang Y, Heeley E, Skulina C, Parsons MW, Peng B, Li Q, Su S, Tao QL, Li YC, Jiang JD, Tai LW, Zhang JL, Xu E, Cheng Y, Morgenstern LB, Chalmers J, Anderson CS, Investigators I: Significance of perihematomal edema in acute intracerebral hemorrhage: the interact trial. Neurology 2009;73:1963-1968.

119 Gebel JM, Brott TG, Sila CA, Tomsick TA, Jauch E, Salisbury S, Khoury J, Miller R, Pancioli A, Duldner JE, Topol EJ, Broderick JP: Decreased perihematomal edema in thrombolysis-related intracerebral hemorrhage compared with spontaneous intracerebral hemorrhage. Stroke 2000;31:596600.
120 Gebel JM Jr, Jauch EC, Brott TG, Khoury J, Sauerbeck L, Salisbury S, Spilker J, Tomsick TA, Duldner J, Broderick JP: Natural history of perihematomal edema in patients with hyperacute spontaneous intracerebral hemorrhage. Stroke 2002;33:2631-2635.

121 Xue M, Hollenberg MD, Yong VW: Combination of thrombin and matrix metalloproteinase-9 exacerbates neurotoxicity in cell culture and intracerebral hemorrhage in mice. J Neurosci 2006;26:10281-10291.

122 MacLellan CL, Silasi G, Poon CC, Edmundson CL, Buist R, Peeling J, Colbourne $\mathrm{F}$ : Intracerebral hemorrhage models in rat: comparing collagenase to blood infusion. J Cereb Blood Flow Metab 2008;28:516-525.

123 Bullock R, Brock-Utne J, van Dellen J, Blake $\mathrm{G}$ : Intracerebral hemorrhage in a primate model: effect on regional cerebral blood flow. Surg Neurol 1988;29:101-107.

124 Rosenberg GA, Mun-Bryce S, Wesley M, Kornfeld M: Collagenase-induced intracerebral hemorrhage in rats. Stroke 1990;21: 801-807. 